\title{
Development of a Dynamic Modulus Prediction Model for Hot Mixture Asphalt and Study of the Impact of Aggregate Type and Its Electrochemical Properties
}

\author{
Mouhamed Lamine Chérif Aidara1, Makhaly Ba ${ }^{1}$, Alan Carter ${ }^{2}$ \\ ${ }^{1}$ UFR Sciences de l'Ingénieur, Université de Thiès, Thiès, Sénégal \\ ${ }^{2}$ Ecole de Technologie Supérieure (ETS), Director of Pavement Bituminous Materials Laboratory (LCMB), Montréal, Canada \\ Email: mouhamedlamine.aidara@univ-thies.sn
}

How to cite this paper: Aidara, M.L.C., Ba, M. and Carter, A. (2020) Development of a Dynamic Modulus Prediction Model for Hot Mixture Asphalt and Study of the Impact of Aggregate Type and Its Electrochemical Properties. Open Journal of Civil Engineering, 10, 213-225.

https://doi.org/10.4236/ojce.2020.103018

Received: July 4, 2020

Accepted: July 21, 2020

Published: July 24, 2020

Copyright ( 2020 by author(s) and Scientific Research Publishing Inc. This work is licensed under the Creative Commons Attribution International License (CC BY 4.0).

http://creativecommons.org/licenses/by/4.0/

\section{(c) (i) Open Access}

\begin{abstract}
The most famous model known in prediction of dynamic modulus for asphalt concretes is the Witczak and Hirsh models. These models didn't use the mineralogical and chemical properties of aggregates. Witczak models used the passing or refusal percentage to sieve diameters and Hirsh model used the volumetric analysis. All models developed until now considered that the aggregates were geotechnical conforming to standards. In this study the first mineralogical and chemical properties were considered through the percentage of silica in the rock source of aggregates and the electric aggregate particles charge zeta. Dynamic modulus values used for regression process are determined from complex modulus test on nine asphalt concretes mix designed with aggregate types (basalt of Diack, quartzite of Bakel and Limestone of Bandia). Between Twelve initial inputs, the statistical regression by exclusion process keeps only seven parameters as input for the model. The mineralogical model showed good accuracy with $\mathrm{R}^{2}$ equal to 0.09 . The student test on the model parameters showed that all the parameters included in the model were meaningful with good $\mathrm{p}$ inferior to 0.05 . The Fisher test on the model showed the same result. The analysis of the sensitivity of the mineralogical model to zeta potential showed that the dynamic modulus increases with the positive zeta-potentials and decreases with the negative zeta-potentials. The analysis of the sensitivity of the mineralogical model to the silica showed that the dynamic modulus decreases with the increase of the silica.
\end{abstract}

\section{Keywords}

Dynamic Modulus, Mineralogical, Basalt of Diack, Quartzite of Bakel, Limestone of Bandia, Zeta Potential, Silica 


\section{Introduction}

The principal objective of this paper is to develop a partial mineralogical and electrochemical dynamic modulus predictive model for asphalt concretes. Indeed, the impact of aggregate type has never been considered in the dynamic modulus of asphalt concrete or in the interpretations of factor which impacted the dynamic modulus test results. Only the passing and refusals percentage trough the U.S. sieve is considered in the Witczak models [1] [2]. The Hirsh model uses only the volumetric analysis parameters as "Voids in Mineral Aggregate" (VMA) or "Voids Filled with Asphalt" (VFA) [3]. The advanced rheological models do not use the aggregate properties but properties of a spring and a dashpot [4]-[9].

The development of mineralogical model needs results of complex modulus laboratory tests. Study was carried to "Laboratoire des Chaussées et Matériaux Bitumineux" (LCMB). Formulation of nine asphalt concretes was made with three aggregate types: basalt of Diack, quartzite of Bakel and limestone of Bandia [10] [11] [12] [13] and one type of asphalt binder (PG 70-16).

For each mixture, test temperatures used during test were $0^{\circ} \mathrm{C}, 10^{\circ} \mathrm{C}, 20^{\circ} \mathrm{C}$, $40^{\circ} \mathrm{C}$ and $55^{\circ} \mathrm{C}$ and for each temperature frequencies used were $0.1 \mathrm{~Hz}, 0.3 \mathrm{~Hz}, 1$ $\mathrm{Hz}, 5 \mathrm{~Hz}$ and $10 \mathrm{~Hz}$. For the development of the mineralogical model, statistical analysis is used on Statistica software. But a primary choice of parameters for the mineralogical model must be done.

\section{Methodology}

\subsection{The Mineralogical Model Parameters, Test Process and Results}

For the bitumen, it was decided to keep the selection of the complex shear modulus $\left|G^{*}\right|$ and phase angle $\delta_{b}$ for each test temperature and frequency. Note that the viscosity related to temperature and frequency can also be used to take into account the impact of the bituminous binder on the prediction [6] [7] [9] [14]. For aggregates, the impact of mineralogy was assigned to the zeta potential $(\zeta)$ and $\mathrm{SiO}_{2}$ content $\left(\mathrm{TSiO}_{2}\right)$. Silica is a component of almost all rock types. The granularity of the mineral structure is related to the specific surface of the aggregate mixture noted $\Sigma$. Indeed, more an aggregate mixture is coarse, more its specific surface andits binder content are also higher. Mineralogy also affects the hardness of the rock, which will be translated by the coefficients Micro Deval and Los Angeles (Table 1). Note that these parameters are directly related to the content of $\mathrm{SiO}_{2}$. Volumetric properties of the bituminous mixture are the thickness of the bitumen film $(h)$, the effective binder content $\left(V_{\text {beff }}\right)$ and the void percentage $\left(V_{a}\right)$.

\subsection{The Silica $\left(\mathrm{SIO}_{2}\right)$}

Pure Silica is very hard mineral which exist in several forms. It is the principal 
Table 1. Physical properties of common rocks [17].

\begin{tabular}{ccccccc}
\hline Rock type & $\begin{array}{c}\mathrm{SiO}_{2} \\
(\%)\end{array}$ & $\begin{array}{c}\text { Specific } \\
\text { gravity }\end{array}$ & Crushability & $\begin{array}{c}\text { Los } \\
\text { Angeles }\end{array}$ & $\begin{array}{c}\text { Dynamic } \\
\text { fragmentation }\end{array}$ & $\begin{array}{c}\text { Abrasi } \\
\text { veness }\end{array}$ \\
\hline Basalt & $20-50$ & $2.7-3.1$ & $20-44$ & $8-21$ & $11-32$ & $500-2300$ \\
Diabase & $45-55$ & $2.6-3.1$ & $18-44$ & $7-34$ & $11-21$ & $450-2300$ \\
Diorite & $55-70$ & $2.6-2.9$ & $20-36$ & $14-30$ & $13-24$ & $400-1700$ \\
Dolomite & $0-10$ & $2.6-3.0$ & $30-56$ & $15-55$ & $20-38$ & $20-250$ \\
Gabbro & $40-55$ & $2.7-3.0$ & $27-34$ & $14-30$ & $15-19$ & $800-1700$ \\
Gneiss & $55 / 75$ & $2.6-2.8$ & $30-67$ & $15-28$ & $12-42$ & $600-1600$ \\
Granit & $65-75$ & $2.6-2.8$ & $28-90$ & $17-35$ & $17-41$ & $900-1900$ \\
Limestone & $0-30$ & $2.4-2.8$ & $30-45$ & $30-45$ & $28-44$ & $0-500$ \\
Quartzite & $90-99$ & $2.5-2.7$ & $22-65$ & $17-40$ & $14-40$ & $1400-2400$ \\
\hline
\end{tabular}

component of detrital sedimentary rocks. Silica represents $27 \%$ of Earth crust and $95 \%$ of silicate minerals [15].

Silica is represented by quartz in metamorphic and magmatic rock, and by crystalized or amorphous forms in volcanic rock [16]. Silica can crystalize in several mineral depending on crystallization temperature and pressure. Table 1 shows that physicals properties considered in geotechnical standard are linked to rock silica content [17].

\subsection{The Zeta Potentiel}

Zeta potential is the electrical charge that a particle acquires through ion cloud surrounding when it is suspended (Figure 1). It is an excellent indicator of the interaction between charged particles and therefore the stability of colloids, such as emulsions or suspended particles. The measurement of zeta potential allows to predict the behavior of emulsions and suspensions (stability, creaming, coalescence, agglomeration ...), and therefore to understand the mix design matters. The zeta potential can be positive (cationic) or negative (anionic), it will depend on the stability of the suspended particles of a total interaction potential [18].

When the Zeta-meter 4.0 is used, the zeta potential is calculated by the Smoluchowski equation [9] (Equation (1)), which is one of these most basic expressions.

$$
\zeta=\frac{113.000 \times V_{t}}{D_{t}} \times E M
$$

With:

$E M=$ electrophoretic mobility at the given temperature;

$V_{t}=$ the viscosity of the suspension liquid at the temperature $\mathrm{t}$ (poise);

$D_{t}=$ the dielectric constant;

$\zeta=$ Zeta potential in millivolts $(\mathrm{mV})$.

To study the behavior of fine aggregates investigated in aqueous solutions, 

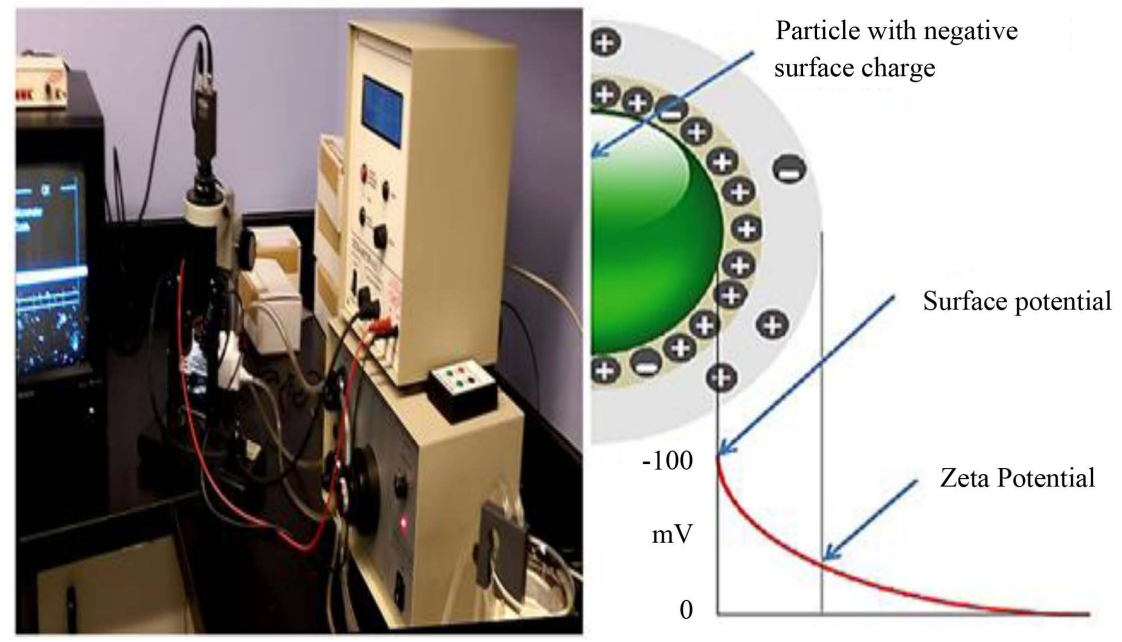

Figure 1. Zeta Potential equipment and illustration [18].

zeta potential measurements were performed at different $\mathrm{pH}$ (acidic, neutral and basic) to the laboratory of the "Experimental Station of Environmental Pilot Processes" (STEPPE) at "Ecole de Technologie Supérieure" (ETS). Aqueous solutions were prepared using stock solutions of $\mathrm{HCl}$ acid and base $\mathrm{NaOH}$. Table 2 presents the zeta potential test results for the basalt of Diack, quartzite of Bakel and Limestone of Bandia at room temperature $\left(25^{\circ} \mathrm{C} \pm 2^{\circ} \mathrm{C}\right)$. These results shows that for the acidic $\mathrm{pH}$ aqueous solutions quartzite of Bakel has a positive potential $(\mathrm{mV}=+22.58)$ higher than that of basalt $(=+18.87 \mathrm{mV})$ which is greater than that of the limestone $(=+13.32 \mathrm{mV})$. This implies that for a given acidic solution, limestone will establish less electrostatic connection type than basalt and quartzite, which is more likely to build links. For "neutral" pH and alkaline solution, basalt and quartzite particles have substantially the same values (respectively $+37.07 \mathrm{mV},+38.63 \mathrm{mV},+38.52 \mathrm{mV}$ and $+37.89 \mathrm{mV}$ ). The limestone has the lowest values with $+16.41 \mathrm{mV}$ and $+18.86 \mathrm{mV}$. This implies that for solutions to $\mathrm{pH}$ greater than 7.12 (basic), particles of basalt and quartzite are more likely to establish electrostatic connection type that the limestone particles.

\subsection{The Specific Surfaces Area and the Film Thickness of Binder}

There are several expressions of the specific surface for aggregate skeleton for asphalt concretes. In French mix design method the specific surface is used to calculate de binder content [19]. In Superpave mix design method, it is used to calculate the film thickness of binder [14]. But for the purely empirical character of the specific surface formulas, none of them is better than the other [14].

In this study the expression of the specific surface is given by the Equation (2) [19].

$$
\Sigma\left(\mathrm{m}^{2} / \mathrm{kg}\right)=\frac{1}{100}(0.25 G+2.30 S+12 \mathrm{~s}+135 f)
$$

With: 
Table 2. Zeta potential test results.

\begin{tabular}{cccc}
\hline \multirow{2}{*}{ Aggregates type } & \multicolumn{3}{c}{ Zeta potentiel } \\
\cline { 2 - 4 } & $\mathrm{pH}=\mathbf{5 . 0 2}$ & $\mathrm{pH}=7.12$ & $\mathrm{pH}=9.08$ \\
\hline Basalte of Diack & 19.87 & 37.07 & 38.63 \\
Quartzite of Bakel & 22.58 & 38.52 & 37.89 \\
Limestone of Bandia & 13.32 & 16.41 & 18.66 \\
\hline
\end{tabular}

$G=$ gravel $>5 \mathrm{~mm}(\%)$;

$S=$ coarse medium sand $(0.315<S<5 \mathrm{~mm})(\%)$;

Sand, $s=(0.08<s<0.315)(\%)$;

$f=$ filler $<80 \mu(\%)$.

The thickness of the binder film is calculated by Equation (3) (NCHRP, 2004).

$$
\mathrm{AFT}=\frac{1000 \mathrm{VBE}}{\Sigma P_{s} G_{m b}}
$$

With:

$\mathrm{AFT}=$ thickness of the binder film $(\mu \mathrm{m})$;

$\mathrm{VBE}=$ effective binder content in percentage of volume (\%);

$\Sigma=$ specific surface area $\left(\mathrm{m}^{2} / \mathrm{kg}\right)$;

$P_{s}=$ aggregate percentage in the mixture (100-binder content) (\%);

$G_{m b}=$ bulk specific gravity of compacted asphalt.

\subsection{The Dynamic Shear Modulus $\left|G^{*}\right|$ and Phase Angle $\delta_{b}$ of Asphalt Binder}

Complex shear modulus test for asphalt binder $G^{*}$ are performed according to American standards (ASTM DD7552-09) [20] to several temperatures $\left(0^{\circ} \mathrm{C}\right.$, $10^{\circ} \mathrm{C}, 20^{\circ} \mathrm{C}, 30^{\circ} \mathrm{C}, 40^{\circ} \mathrm{C}$ and $55^{\circ} \mathrm{C}$ ) and several frequencies for each temperature $(0.1 \mathrm{~Hz}, 0.3 \mathrm{~Hz}, 1 \mathrm{~Hz}, 5 \mathrm{~Hz}$ et $10 \mathrm{~Hz})$.

\subsection{The Volumetric Analysis Parameters}

The volumetric parameters used in the mineralogical model are the effective binder content $\left(V_{\text {beff }}\right)$ and the void content $\left(V_{a}\right)$.

\subsection{Complex Modulus Test}

Asphalt mixes Complex modulus tests (Dynamic modulus) were performed using the Direct Traction-Compression (DTC) test on cylindrical samples according to Canadian or European standards, respectively LC 26-700 [21] and NF EN 12697-26 [22]. Nine mixtures were studied (three basalt asphalt concretes, three quartzite asphalt concretes and three limestone asphalt concretes). Each formula undergoes measurements at temperatures of $0^{\circ} \mathrm{C}, 10^{\circ} \mathrm{C}, 20^{\circ} \mathrm{C}, 30^{\circ} \mathrm{C}, 40^{\circ} \mathrm{C}$ and $55^{\circ} \mathrm{C}$ and for each temperature the frequencies are $10 \mathrm{~Hz}, 5 \mathrm{~Hz}, 1 \mathrm{~Hz}, 0.3 \mathrm{~Hz}$ and $0.1 \mathrm{~Hz}$. Table 3 shows partial database parameters for each mix studied. 
Table 3. Presentation of partial database for mineralogical model development.

\begin{tabular}{|c|c|c|c|c|c|c|c|c|c|c|}
\hline Mix & $T^{\circ} \mathrm{C}$ & $\begin{array}{c}f \\
\mathrm{~Hz}\end{array}$ & $\begin{array}{l}V_{b e f f} \\
(\%)\end{array}$ & $\begin{array}{c}V_{a} \\
(\%)\end{array}$ & $\log \left(\delta_{b}\right)$ & $\begin{array}{c}\sum \\
\mathrm{m}^{2} / \mathrm{kg}\end{array}$ & $\begin{array}{c}\zeta \\
\text { basic } \mathrm{pH}\end{array}$ & $\begin{array}{l}T_{\mathrm{SiO}_{2}} \\
(\%)\end{array}$ & $\begin{array}{c}\log \left|G^{*}\right| \\
\text { measured }\end{array}$ & $\begin{array}{c}\log \left|E^{*}\right| \\
\text { measured }\end{array}$ \\
\hline BDF & -0.1 & 10.0 & 11.34 & 8.77 & 0.56 & 13.76 & 38.63 & 46.00 & $8.01 \mathrm{E}-01$ & 4.19 \\
\hline BDF & -0.1 & 3.0 & 11.34 & 8.77 & 0.84 & 13.76 & 38.63 & 46.00 & $8.01 \mathrm{E}-01$ & 4.15 \\
\hline BDD & 1.0 & 10.0 & 12.25 & 5.05 & 0.49 & 11.50 & 38.63 & 46.00 & $7.99 \mathrm{E}-01$ & 4.05 \\
\hline BDD & 1.1 & 3.0 & 12.25 & 5.05 & 0.82 & 11.50 & 38.63 & 46.00 & $7.99 \mathrm{E}-01$ & 3.99 \\
\hline BDC & 20.30 & 1.0 & 11.00 & 8.91 & 1.50 & 7.82 & 38.63 & 46.00 & $6.12 \mathrm{E}-01$ & 3.43 \\
\hline BDC & 20.15 & 0.3 & 11.00 & 8.91 & 1.57 & 7.82 & 38.63 & 46.00 & $6.15 \mathrm{E}-01$ & 3.24 \\
\hline GDF & 0.9 & 10.0 & 11.64 & 5.28 & 0.49 & 15.00 & 38.89 & 94.50 & $7.99 \mathrm{E}-01$ & 4.12 \\
\hline GDF & 0.9 & 3.0 & 11.64 & 5.28 & 0.82 & 15.00 & 38.89 & 94.50 & $7.99 \mathrm{E}-01$ & 4.06 \\
\hline GDD & 0.1 & 10.0 & 11.50 & 2.19 & 0.55 & 13.43 & 38.89 & 94.50 & $8.00 \mathrm{E}-01$ & 4.25 \\
\hline GDD & 0.1 & 3.0 & 11.50 & 2.19 & 0.83 & 13.43 & 38.89 & 94.50 & $8.00 \mathrm{E}-01$ & 4.20 \\
\hline GDC & 0.4 & 10.0 & 11.12 & 6.95 & 0.53 & 12.19 & 38.89 & 94.50 & $8.00 \mathrm{E}-01$ & 4.04 \\
\hline GDC & 0.4 & 3.02 & 11.12 & 6.95 & 0.83 & 12.19 & 38.89 & 94.50 & $8.00 \mathrm{E}-01$ & 3.98 \\
\hline $\mathrm{CDF}$ & 0.6 & 10.0 & 6.97 & 16.44 & 0.52 & 11.18 & 18.66 & 0.70 & $8.00 \mathrm{E}-01$ & 3.01 \\
\hline $\mathrm{CDF}$ & 0.5 & 3.0 & 6.97 & 16.44 & 0.83 & 11.18 & 18.66 & 0.70 & $8.00 \mathrm{E}-01$ & 2.99 \\
\hline CDD & 0.6 & 10.0 & 7.23 & 12.85 & 0.52 & 8.47 & 18.66 & 0.70 & $8.00 \mathrm{E}-01$ & 3.89 \\
\hline CDD & 0.4 & 3.0 & 7.23 & 12.85 & 0.83 & 8.47 & 18.66 & 0.70 & $8.00 \mathrm{E}-01$ & 3.86 \\
\hline $\mathrm{CDC}$ & -0.1 & 10.0 & 6.23 & 13.93 & 0.56 & 5.97 & 18.66 & 0.70 & $8.01 \mathrm{E}-01$ & 3.91 \\
\hline $\mathrm{CDC}$ & -0.2 & 3.0 & 6.23 & 13.93 & 0.84 & 5.97 & 18.66 & 0.70 & $8.01 \mathrm{E}-01$ & 3.88 \\
\hline
\end{tabular}

$\left|E^{\star}\right|=$ dynamic complex modulus $(\mathrm{MPa}) ; V_{\text {beff }}=$ effective binder content as a percentage of volume; $V_{a}=$ percentage of void volume percentage; $\delta_{b}=$ phase angle of the bituminous binder $\left(^{\circ}\right) ; \zeta=$ Zeta potential $(\mathrm{mV}) ; \mathrm{SiO}_{2}$ content of the source of aggregate rock; $\left|G^{*}\right|=$ dynamic shear modulus (MPa); $\Sigma=$ surface area of the mineral skeleton of the mixes $\left(\mathrm{m}^{2} / \mathrm{kg}\right)$.

\section{Statistical Development Methodology of Mineralogical Predictive Model and Interpretations}

Multiple linear regressions (polynomial) by descending exclusion (step by step) are used in the development of mineralogical model prediction of the dynamic modulus of asphalt concrete studied. Statistical development tool used is statistical software [23]. In the matrix of linear regression statistical methods, the distribution of the error $\mathcal{\varepsilon}$ is independent of $X$, the error is centered and constant variance and the parameters (constants) model are constant. The estimation of the model constants are obtained by minimizing the average prediction error or SSD. Evaluation of regression models based on the adjusted value of the multiple correlation coefficient noted (which marks the degree of binding between the variable to predict and the predictors) and significance tests (Student test and Fischer test). The Equation (4) gives expression.

$$
R_{a}^{2}=1-\frac{(N-1) \times\left(1-R^{2}\right)}{N-p-1}
$$


With:

$R_{a}^{2}=$ Adjusted coefficient of multiple determination;

$N=$ number of observations;

$p=$ number of variables;

If the data are limited to 30 samples. We must use the coefficient of determination $R^{2}$ (Equation (5)).

$$
R^{2}=\frac{\mathrm{SCR}_{\mathrm{e}} g}{\mathrm{SCT}}
$$

With:

$\mathrm{SCR}_{\mathrm{e}} \mathrm{g}=$ sum of squared deviations of the model;

SCT $=$ total sum of squared deviations.

Student's $\mathrm{t}$ test is used to check whether each parameter is statistically significant before introducing it in the model. The Fisher test checks the significance model itself. These two tests are related to the p-value and a test is significant if the $\mathrm{p}$-value less than 0.05 . The database is composed by 271 points of dynamic complex modulus data. After several simulations process on a statistical software, the selected model is given by the Equation (6).

$$
\begin{aligned}
& \log \left|E^{*}\right|_{\text {SILICE-ZETA }} \\
= & 2.88487656+0.366038859 V_{\text {beff }}-0.03864789 V_{\text {beff }}^{2}-0.0073155 V_{a}^{2} \\
& +2.72454806 \log \delta_{b}-1.6527836 \log \delta_{b}^{2}+0.3947615 \zeta \\
& -0.8851 \mathrm{E}-4 T_{\mathrm{SiO}_{2}}^{2}-0.37305171 \log \left|G^{*}\right|^{2}+0.002125823 \Sigma^{2}
\end{aligned}
$$

With:

$\left|E^{*}\right|_{\text {SILICE-ZETA }}=$ dynamic complex modulus (MPa);

$V_{\text {beff }}=$ effective binder content as a percentage of volume;

$V_{a}=$ percentage of void volume percentage;

$\delta_{b}=$ phase angle of the bituminous binder $\left({ }^{\circ}\right)$;

$\zeta$ = zeta potential $(\mathrm{mV})$;

$\mathrm{SiO}_{2}=$ content of the source of aggregate rock;

$\left|G^{*}\right|=$ dynamic shear modulus (MPa);

$\Sigma=$ surface area of the mineral skeleton of the mixes $\left(\mathrm{m}^{2} / \mathrm{kg}\right)$.

Table 4 shows the statistical exclusion development approach. The statistical analysis of the mineralogical model (Figure 2) gives a good coefficient of determination of 0.90 (the same as $R_{a}^{2}$ ). This means that the predictors are related to $90 \%$ to predictive model. Fisher's test performed on mineralogical model has good significance ( $p=0.000$, less than 0.05$)$. Student's test on the predictors (Table 4) shows significance (all $p$ are less than 0.05$)$. The variables $\left(V_{b e f f} V_{a}\right.$, $\log \left(\delta_{b}\right), \sum$ and $\left.\mathrm{TSiO}_{2} \log \left|G^{\star}\right|\right)$ present the best significances $(p=0.000)$. The zeta potential seems to be the least significant variable ( $p=0.000047)$, but very good.

\section{Study of the Sensitivity of Mineralogical Model}

\subsection{Aggregate Impact}

To check whether if all types of aggregates used in the study (basalt of Diack, 


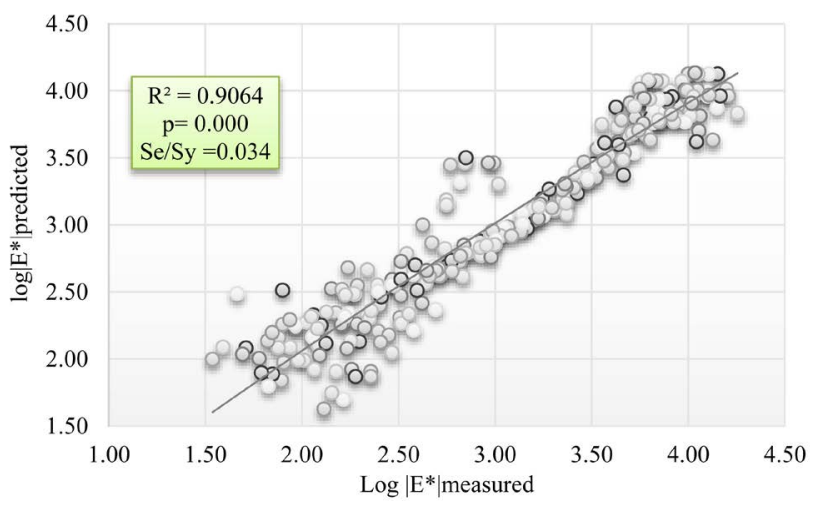

Figure 2. Correlation between $\log \left|E^{*}\right|$ predicted and $\log \left|E^{\star}\right|$ Measured (all asphalt concretes)

Table 4. Statistical exclusion development approach (23).

\begin{tabular}{|c|c|c|c|c|c|}
\hline & SC & Degree of-Liberty & MC & F & $\mathrm{p}$ \\
\hline Ord. Orig. & 1.08826 & 1 & 1.08826 & 22.6891 & 0.000003 \\
\hline$V_{\text {beff }}$ & 0.30535 & 1 & 0.30535 & 6.3663 & 0.012228 \\
\hline$V_{\text {beff }}^{2}$ & 1.30081 & 1 & 1.30081 & 27.1205 & 0 \\
\hline$V_{a}$ & 0 & 0 & 0 & 0 & 0 \\
\hline$V_{a}^{2}$ & 7.06054 & 1 & 7.06054 & 147.2048 & 0 \\
\hline $\log \left(\delta_{b}\right)$ & 5.16039 & 1 & 5.16039 & 107.5885 & 0 \\
\hline $\log \left(\delta_{b}\right)^{2}$ & 13.40954 & 1 & 13.40954 & 279.5745 & 0 \\
\hline$\zeta$ & 0.8229 & 1 & 0.8229 & 17.1566 & 0.000047 \\
\hline$\xi^{2}$ & 0 & 0 & 0 & 0 & 0 \\
\hline$T_{\mathrm{SiO}_{2}}$ & 0 & 0 & 0 & 0 & 0 \\
\hline$T_{\mathrm{SiO}_{2}}^{2}$ & 5.21807 & 1 & 5.21807 & 108.7911 & 0 \\
\hline $\log \left|G^{*}\right|$ & 0 & 0 & 0 & 0 & 0 \\
\hline $\log \left|G^{*}\right|^{2}$ & 1.99868 & 1 & 1.99868 & 41.6703 & 0 \\
\hline$\Sigma$ & 0 & 0 & 0 & 0 & 0 \\
\hline$\Sigma^{2}$ & 1.05976 & 1 & 1.05976 & 22.0949 & 0.000004 \\
\hline Error & 12.47066 & 260 & 0.04796 & 0 & 0 \\
\hline
\end{tabular}

$\left|E^{\star}\right|=$ dynamic complex modulus (MPa); $V_{\text {beff }}=$ effective binder content as a percentage of volume; $V_{a}=$ percentage of void volume percentage; $\delta_{b}=$ phase angle of the bituminous binder $\left(^{\circ}\right)$; = Zeta potential $(\mathrm{mV}) ; \mathrm{SiO}_{2}$ content of the source of aggregate rock; $\left|G^{*}\right|=$ dynamic shear modulus (MPa); $\Sigma=$ surface area of the mineral skeleton of the mixes $\left(\mathrm{m}^{2} / \mathrm{kg}\right)$.

quartzite of Bakel and limestone of Bandia) positively participate and to what degree in the accuracy of mineralogical model, correlation studies were conducted separately with the test results of each type of aggregate.

The results of correlations show that the basalt was alone shows an accuracy of $R^{2}=0.97$ (Figure 3). The quartzite asphalt concretes fairly similar to basalt 


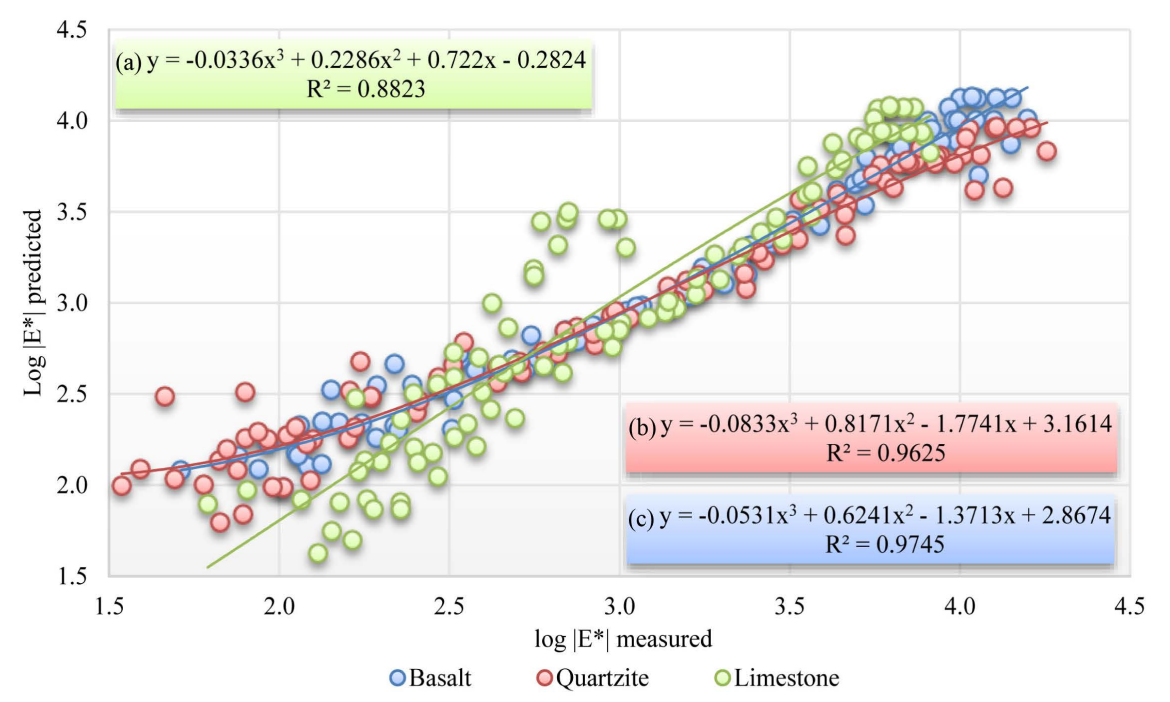

Figure 3. Correlation of basalt (a), quartzite (b) and limestone (c) asphalt Concretes.

shows good correlation of the measure modulus and predicted modulus by the mineralogical model. Its coefficient of determination is $R^{2}=0.96$ (Figure 3). Limestone asphalt concretes show also shows good correlation $\left(R^{2}=0.88\right)$. Figure 3 shows that the overflowing data points in Figure 2 are limestone data points.

\subsection{Zeta Potential Impact}

To study the impact of the zeta potential on the mineralogical model and thus indirectly on the dynamic modulus of asphalt mixtures the approach consist to choose an asphalt mix for each type of aggregate. Selected options are the CDC, the BDC and the GDC. For each formula, a theoretical variation of the zeta potential will be conducted to measure its impact on the predicted dynamic modulus. Figure 4 shows the results for the Zeta positive and negative potentials.

Figure 4 shows that for asphalt concrete mix designed with a bitumen (PG 70-16), positive zeta potential make a positive effect on the evolution of the dynamic modulus predicted whatever the type aggregate considered. This confirms the effect of attraction. Differences modulus observed are related to the fact that the aggregates have originally different zeta potentials. An important note here is that even for a zeta potential of 16 the CDC modulus is greater than the BDC and the GDC. This is normal because the limestone have a greater Nominal Maximum Aggregate Size (NMAS $=25 \mathrm{~cm}$ ), which mitigates the effect of the hardness of basalt and sandstone. For negative zeta potentials, a decreasing of dynamic modulus values is observed, based on the drop in zeta potential. This confirms the repulsion effect. But in the case of negative zeta potential, the mineralogical model has a lower limit beyond which the prediction is impossible (negative values). Figure 4 shows that this limit is reached at $-40 \mathrm{mV}$ to $-50 \mathrm{mV}$ and GDC for the BDC. Extrapolating the limits of the CDC is obtained at -70 $\mathrm{mV}$. 

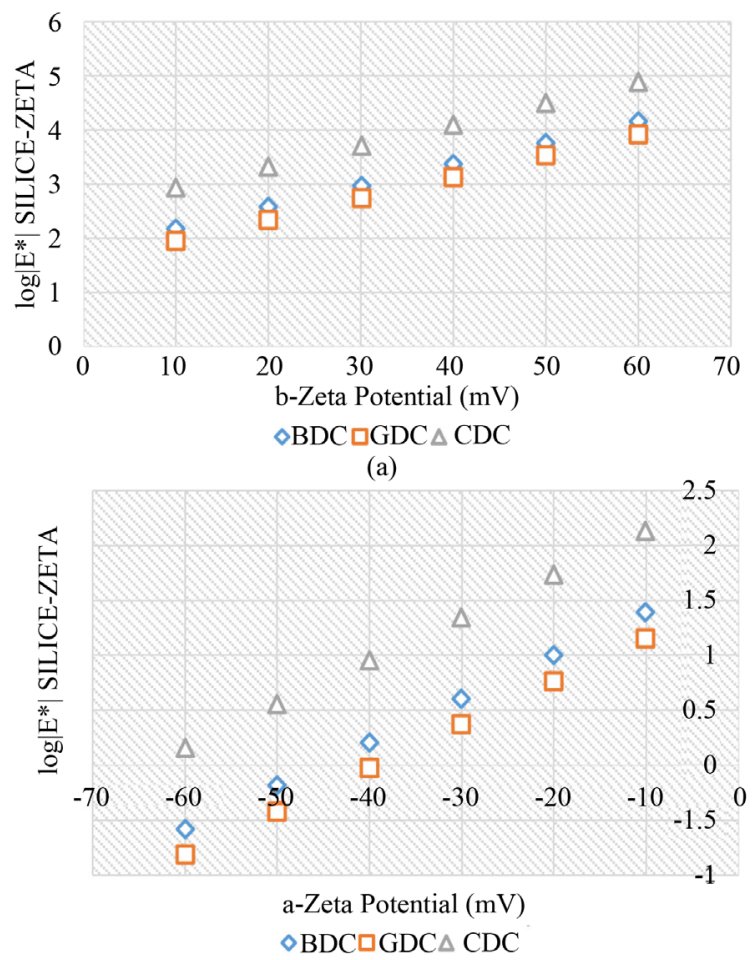

(b)

Figure 4. Effect of change in positive (a) and negative zeta potentials (b) on the dynamic modulus $\left(30^{\circ} \mathrm{C}\right.$ and $\left.10 \mathrm{~Hz}\right)$.

\subsection{Silica Content Impact}

To study the influence of $\mathrm{SiO}_{2}$ content, the same scenario as the zeta potential was adopted. A theoretical variation of $0 \%$ to $100 \% \mathrm{SiO}_{2}$ was considered and the effects on the dynamic modulus predicted were calculated.

Figure 5 shows that the increase of aggregate $\mathrm{SiO}_{2}$ content has a negative effect on the predicted dynamic modulus of asphalt mixtures, because the mineral composition of an aggregate cannot change during formulation this observation is handled with caution. However the physical interpretation of this result is difficult because it can move in several directions, as complex as the presence in quantity and quality of silica in the rock. Mechanically by lower aggregate surface properties (roughness drop) due to the increase of the silica but also the form in which it is located. Chemically by increasing electro negativity due to the silica. Dynamic shear modulus testing of bituminous mastics improvement with silica powder can verify this observation.

\subsection{Impact Parameters Not Related to the Nature of the Aggregate}

Simulations with other model parameters showed that:

- An increase of $V_{a}$ in the model leads to a decrease in the dynamic modulus predicted, and an increasing of the effective binder content also leads to a lower module; 


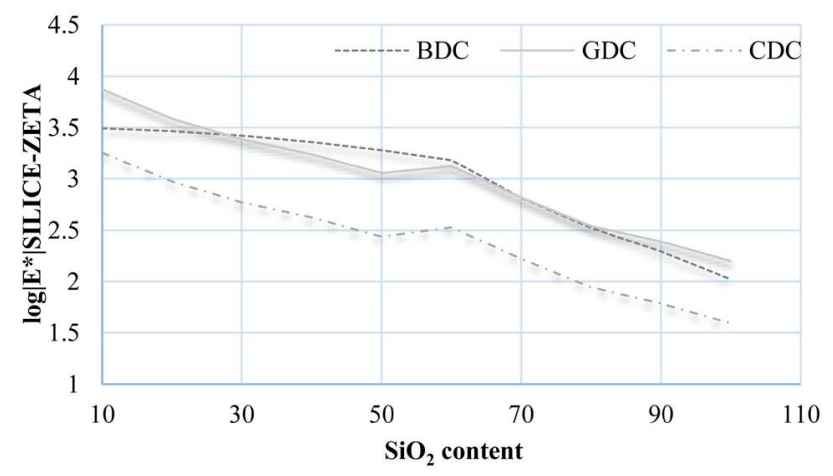

Figure 5. Influence of $\mathrm{SiO}_{2}$ content on the dynamic modulus.

- The surface area is the effective binder content and increasing the specific surface area must always be accompanied by an increase in the $V_{\text {beff. }}$ Increasing the surface area taken individually leads to an increase of the dynamic modulus;

- The influence of asphalt parameters $\left(\left|G^{*}\right|\right.$ and $\left.\delta_{b}\right)$ is more difficult to perform. Indeed, if we consider the module $\left|G^{*}\right|$ separately, its increase causes a fall of the dynamic modulus predicted. But considering also the change of the phase angle, an increase in the predicted dynamic modulus is observed;

- This verifies that the module link $\left|G^{*}\right|$ to $\delta_{b}$ phase angle, increasing the asphalt's modulus as a function of the binder and the degree of susceptibility as a function of frequency and temperature module.

\section{Conclusion}

The development of mineralogical model allowed to indirectly study the impact of aggregate on dynamic modulus of asphalt mixtures, through the variation of the mineralogical composition $\left(\mathrm{TSiO}_{2}\right)$ and chemical composition (zeta potential). Unlike other developed prediction model, it allows a good prediction of the dynamic modulus for asphalt concretes mix designed with road and non-road aggregates. But with better accuracy for road aggregates with middle and high silica content, the study showed that sensitivity increases with the positive zeta potentials aggregates and aggregate decreases with negative zeta potentials, bringing to highlight the phenomena of attraction and repulsion between charged mineral particles. The "increase" of silica in the aggregate also causes a decrease of the dynamic modulus. However, the variation of the content of silica is impossible to carry out in an aggregate and its nature is not uniform in all aggregates. This phenomenon can affect aggregates at its mechanical and/or chemical properties, making it difficult the physical interpretation of the impact of silica. But this hypothesis can still be checked by dynamic shear tests on bituminous mastics or the possibility of varying the silica content is possible.

\section{Acknowledgements}

The authors would like to acknowledge the team of LCMB. 


\section{Conflicts of Interest}

The authors declare no conflicts of interest regarding the publication of this paper.

\section{References}

[1] Andrei, D., Mirza, W. and Witczak, M.W. (1999) Development of a Revised Predictive Model for the Dynamic (Complex) Modulus of Asphalt Mixtures. NCHRP Report 1-37A.

[2] Bari, J. and Witczak, M.W. (2006) Development of a New Revised Version of the Witczak E* Predictive Model for Hot Mix Asphalt Mixtures. Journal Association of Asphalt Paving Technologists, 75, 381-424.

[3] Christensen, D.W. (2003) Hirsch Model for Estimating the Modulus of Asphalt Concrete. Journal Association of Asphalt Paving Technologists, 72, 97-121.

[4] Salençon, J. (2009) Viscoelasticity for Calculating the Structure. Paliseau: Journal of Pavements and Bridges. Polytechnical School Edition.

[5] Salençon, J. (1982) Viscoelasticity: During Calculation of Inelastic Structures. Paris: Journal of National School of Pavements and Bridges. Polytechnical School Edition, $88 \mathrm{p}$.

[6] Di Benedetto, H.V. and Corté, F. (2005) Matériaux (Vol. 2). H. Science, Edition. Lavoisier, Lyon.

[7] Olard, F. (2004) Thermomechanical Behavior of Asphalt Mixtures at Low Temperature (Unpublished Doctoral Dissertation). National School of Public Works of the State, University of Claude Bernard Lyon1, State of France.

[8] Aidara, M.L.C., Ba, M. and Carter, A. (2015) Choice of an Advanced Model for Asphalt Concrete Rheological from Senegal (West Africa). Open Journal of Civil Engineering, 5, 289-298. https://doi.org/10.4236/ojce.2015.53029

[9] Aidara, M.L.C., Ba, M. and Carter, A. (2015) Measurement of Dynamic Modulus Master Curve and Modeling of Hot Mix Asphalt from Senegal (West Africa). Studies in Engineering and Technology, 2, 124-135. https://doi.org/10.11114/set.v2i1.936

[10] Dia, A. (1982) Contribution to the Study of Petrographic, Petrochemical and Geotechnical Characteristics of the Basaltic Aggregates of the Cape Verde Peninsula and Plateau Thies (Career Diack Senegal). 3rd Cycle Doctoral Thesis, Fac. Sciences, UCAD, $181 \mathrm{p}$.

[11] Dabo, M. (2007) Structural. Characterization Petrographic and the Chain of the Southern Mauritanides (Bakel Region, Eastern Senegal). Third Cycle PhD Thesis, University of Cheikh Anta Diop, Dakar, 190.

[12] Ba, M. (2012) Mechanical Behavior under Cyclic Solicitations Aggregates Backel of quartzite. Comparison of Senegal and Reference Materials "America (USA): Application to Flexible Pavements Dimensioning of Mechanistic". Thesis Cheikh Anta Diop University of Dakar, Dakar, 239.

[13] Dione, A. (2014) Estimation du Module réversible de Graves Non Traitées et modélisation par éléments finis de chaussées souples en vue d'un dimensionnement mécanistique-empirique. Thèse de Doctorat Université de Thiès, Thies, 183.

[14] Advanced Asphalt Technologies, LLC. (2011) A Manual for Design of Hot Mix Asphalt with Commentary (NCHRP Report 673). TRB, National Research Council, 
Washington DC, 285.

[15] Futura-Science.

http://www.futura-sciences.com/magazines/terre/infos/dossiers/d/geologie-coeur-si lice-silex-wafer-567/page/4

[16] Rudnick, R.L. and Gao, S. (2005) Treatise on Geochemistry, Vol. 3: The Crust. Elsevier,¡Amsterdam, 48-53.

[17] Metso Minerals (2010) Rock Test Report 20108054. Metso Mineral Research and Test Center.

[18] Cordouan Technologies (2015). http://www.cordouan-tech.com/fr/produits/analyse-physico-chimique/caracterisati on-de-particules/potentiel-zeta-wallis

[19] Arrambide, J. and Duriez, M. (1959) Asphalt Concretes and Binder for Pavements: Dunod.

[20] ASTM DD 7552-09 (2009) Standard Test Method for Determining the Complex Shear Modulus $\left(\mathrm{G}^{\star}\right)$ of Bituminous Mixtures Using Dynamic Shear Rheometer.

[21] LC 26-700 (2009) Complex Dynamic Modulus Testing Method. Québec Transportation Agency, Québec.

[22] NF EN 12697-26 (2012) Bituminous Mixtures, Mixture Testing Method: Stiffness modulus. French Standard Association.

[23] StatSoft. http://www.statsoft.com/Textbook/Multiple-Regression 